\title{
An Organic Rankine Cycle Bottoming a Diesel Engine Powered Passenger Car
}

\author{
Antonio Mariani ${ }^{1, *}$, Maria Laura Mastellone ${ }^{2}$, Biagio Morrone ${ }^{1}\left(0\right.$, Maria Vittoria Prati $^{3}(\mathbb{C}$ and \\ Andrea Unich 1 \\ 1 Department of Engineering, Università degli studi della Campania "Luigi Vanvitelli", Via Roma 29, \\ 81031 Aversa CE, Italy; biagio.morrone@unicampania.it (B.M.); andrea.unich@unicampania.it (A.U.) \\ 2 Department of Environmental, Biological and Pharmaceutical Sciences and Technologies, Università degli \\ studi della Campania “Luigi Vanvitelli", Viale Abramo Lincoln, 5, 81100 Caserta CE, Italy; \\ marialaura.mastellone@unicampania.it \\ 3 Consiglio Nazionale delle Ricerche, Istituto Motori, Via Guglielmo Marconi, 4, 80125 Napoli NA, Italy; \\ m.v.prati@im.cnr.it \\ * Correspondence: antonio.mariani@unicampania.it; Tel.: +39-081-5010287
}

Received: 9 December 2019; Accepted: 3 January 2020; Published: 9 January 2020

\begin{abstract}
Organic Rankine Cycle (ORC) power plants are characterized by high efficiency and flexibility, as a result of a high degree of maturity. These systems are particularly suited for recovering energy from low temperature heat sources, such as exhaust heat from other plants. Despite ORCs having been assumed to be appropriate for stationary power plants, since their layout, size and weight constraints are less stringent, they represent a possible solution for improving the efficiency of propulsion systems for road transportation. The present paper investigates an ORC system recovering heat from the exhaust gases of an internal combustion engine. A passenger car with a Diesel engine was tested over a Real Driving Emission (RDE) cycle. During the test exhaust gas mass flow rate and temperature have been measured, thus calculating the enthalpy stream content available as heat addition to ORC plant in actual driving conditions. Engine operating conditions during the test were discretized with a 10-point grid in the engine torque-speed plane. The ten discretized conditions were employed to evaluate the ORC power and the consequent engine efficiency increase in real driving conditions for the actual Rankine cycle. N-pentane (R601) was identified as the working fluid for ORC and R134a was employed as reference fluid for comparison purposes. The achievable power from the ORC system was calculated to be between 0.2 and $1.3 \mathrm{~kW}$, with $13 \%$ system efficiency. The engine efficiency increment ranged from $2.0 \%$ to $7.5 \%$, with an average efficiency increment of $4.6 \%$ over the RDE test.
\end{abstract}

Keywords: heat recovery systems; internal combustion engine; organic Rankine cycle; real driving emission test; thermodynamic modeling

\section{Introduction}

Fossil fuel availability and the environmental impact of their usage in energy conversion systems are big concerns for the scientific community, which is focusing on the development of renewable energy sources. With an increasing share, renewable energy sources will replace fossil fuels for power generation, heating and transportation but such process takes time.

During the transition towards an energy economy not anymore dependent on fossil fuels, it is fundamental to maximize the efficiency of the conversion systems, in order to reduce both greenhouse gases [1] and pollutant emissions. Starting from 2021, the EU has defined a $\mathrm{CO}_{2}$ emission target of $95 \mathrm{~g} / \mathrm{km}$ for the average fleet of new cars. This emission level corresponds to a fuel consumption of $4.1 \mathrm{~L} / 100 \mathrm{~km}$ for gasoline or $3.6 \mathrm{~L} / 100 \mathrm{~km}$ for diesel [2] vehicles. 
Light duty vehicles are mainly powered by internal combustion engines, with a contribution to total oil consumption in Europe of around 50\% and accounting for $25 \%$ of the carbon dioxide emissions in 2016 [3]. The efficiency of internal combustion engines for passenger cars can attain values higher than 40\% for diesel [4] and the most advanced spark ignition engines [5], with lower values at part loads.

The heat rejected into the exhaust gases and the cooling system of internal combustion engines is estimated to be $34-45 \%$ of the initial fuel energy in case of spark ignition (SI) engines and $22-35 \%$ for diesel engines [4]. This heat can be recovered into Organic Rankine Cycles (ORC) for additional power generation. According to the operating principle of Rankine cycles, the pressurized working fluid evaporates into a boiler, expands delivering mechanical power and finally reverts to its initial state in a condenser.

ORC bottoming internal combustion engines is recent. The system seems suitable for marine propulsion [6], where the engine mainly operates in steady-state conditions. Furthermore, for such applications there are no relevant size and weight constraints, an aspect still valid for trucks and buses [7]. Conversely, passenger cars have strict mass and size requirements which make the installation of an ORC more difficult.

Optimizing the design and development of the ORC plant is crucial for minimizing system weight, size and cost, as well as for maximizing system efficiency and reliability [8-10].

In the design process, the choice of the ORC working fluid plays a very important role, being decisive for cycle efficiency, environmental impact, and system safety. From a thermodynamic point of view, the fluids are classified depending on the slope of the saturation vapor curve in the Temperature-Entropy (T-s) diagram: fluids with a positive slope are called "dry", those with a negative slope "wet", and fluids having a nearly vertical saturation curve "isentropic". Isentropic or dry fluids are preferred in Rankine Cycles to avoid the presence of liquid droplets during the expansion. However, a dry fluid can leave the expander with substantial unrecovered heat, which is consequently wasted, also increasing the cooling load in the condenser. Eventually, such heat can be used to preheat the fluid at the pump outlet before it enters the boiler. Wet fluids, on the other hand, will need higher turbine inlet temperature to avoid the two-phase region [11]. Latent heat, density and specific heat are also important properties to be considered in choosing the optimal ORC working fluid. Some studies have demonstrated that fluids with high latent heat, high density and low liquid specific heat are preferable as they can absorb more energy from the source in the evaporator, hence requiring low working fluid mass flow rate. Consequently, the size of the system components is reduced, as well as the work absorbed by the pump [12]. Another important thermodynamic property is the freezing point of the fluid, which must be below the lowest operating temperature in the cycle. The fluid must also work in an acceptable pressure range, avoiding too high pressure or high vacuum, which would impact the cost of the system.

As anticipated earlier, the working fluid choice has to deal with safety and environmental concerns. The fluids can be classified according to the National Fire Protection Association (NFPA) 704 Standard [13]. The working fluids are categorized on their health $(\mathrm{H})$, flammability $(\mathrm{F})$ and chemical instability-reactivity hazards, and ranked with values from 1 (low hazard) to 4 (high hazard). The working fluid must also have a low global warming potential (GWP): this is a measure of how much energy the emissions of 1 ton of a gas will absorb over a given period of time, relative to the emissions of 1 ton of carbon dioxide $\left(\mathrm{CO}_{2}\right)$. The larger the GWP, the more a given gas warms the Earth compared to $\mathrm{CO}_{2}$ over that time period [14].

In an ORC system, the energy can be recovered from many heat sources, characterized by different temperatures. Exhaust gases are classified as high-temperature heat sources, with values ranging between 200 and $600^{\circ} \mathrm{C}$, while coolant $\left(80-100^{\circ} \mathrm{C}\right)$, lube oil $\left(80-120^{\circ} \mathrm{C}\right)$ and the charge air cooling (CAC, $30-50{ }^{\circ} \mathrm{C}$ ) are considered low temperature heat sources [15]. Temperature values depend on the engine operating point. In engine waste heat recovery systems, exhaust gas and recycled exhaust gases are commonly exploited due to their high temperature. Conversely, engine coolant, CAC and lube oil heat 
recovery is less common in the literature because of the lower temperature and potential, despite the exploitation of such waste heat could be beneficial for the vehicle thermal management [15]. Usually alcohols (e.g., ethanol, methanol), water steam and hydrocarbons (e.g., benzene, toluene, pentane, octane, cyclohexane, and cyclopentane) are suitable for waste heat recovery from high temperature heat sources, even though some of them display flammability concerns. Mixtures of alcohols with water have also been considered in order to decrease flammability issues. Refrigerants are usually more suitable for low temperature waste heat recovery, such as CAC and coolant.

ORC bottoming engines must also adopt an appropriate condensing strategy. There are some possibilities for engine waste heat recovery in vehicle applications: indirect condensation using the engine cooling circuit as heat sink (temperature range around $80-100^{\circ} \mathrm{C}$ ), indirect condensation using a lower temperature cooling circuit (e.g., CAC, temperature $30-50^{\circ} \mathrm{C}$ ), or direct cooling using an ambient air condenser (installed in the vehicle cooling pack). In the first two cases, the coolant heat must also be rejected to the environment through the vehicle cooling package. Condensing temperature depends on expected ambient conditions. In marine and stationary applications, there are fewer constraints affecting the condenser installation, and the availability of a cooling medium such as sea or fresh water.

Plant architecture and layout should fit with the application type, considering packaging and weight constraints. In fact, while for trucks, off-road engines, power generation engines, as well as marine engines, it is convenient to consider solutions to exploit the lower temperature heat sources to preheat the working fluid before entering the evaporator [16], simple configurations are usually more appropriate for passenger cars [7].

Fitting an ORC system on the exhaust line of an engine increases the weight and complexity of the overall system and increases the exhaust gas backpressure, which could lead to performance degradation. The engine backpressure can be counter-balanced implementing appropriate turbocharging strategies, choosing for example a Variable Geometry Turbine (VGT). Such a solution would help in limiting the negative effect of the increased back pressure caused by the exhaust gas heat exchanger. In fact, it has been demonstrated by means of numerical simulations that, adopting a VGT, the engine brake specific fuel consumption is only weakly affected by the ORC system if the backpressure increase is below 100 mbar [17].

This paper presents the results of a numerical and experimental analysis proposing an ORC system bottoming a compression ignition engine powered passenger car. The aim is the estimation of the recoverable mechanical power and the consequent engine efficiency increase. The available thermal power for the ORC system was measured on a vehicle performing an RDE test. Exhaust gas mass flow rate and temperature were recorded together with engine rotational speed, while engine instantaneous torque was determined taking into consideration the vehicle resistant and inertia forces. A grid of ten points into the torque-speed plane was used for grouping the determined operating conditions, each node being characterized by a residence time, exhaust mass flow rate and temperature values. The actual Rankine cycle was calculated considering the grid node conditions, obtaining the recovered power and the engine efficiency increase. N-pentane (R601) was chosen as working fluid for the ORC while R134a has been considered only for comparison purposes.

\section{Modelling and Analysis}

A sketch of the ORC system investigated in this paper is provided in Figure 1. A simple layout without regeneration was selected with the aim of reducing the system mass and size. 


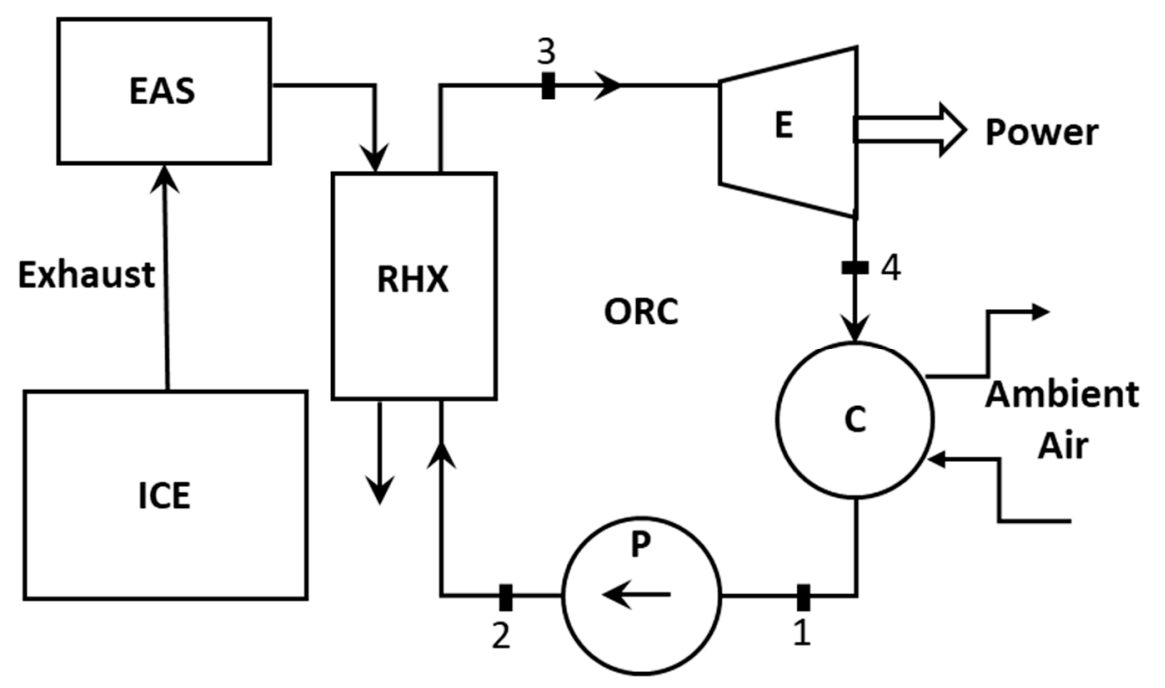

Figure 1. Sketch of the ORC system.

The vehicle considered for ORC system installation was a car powered by a diesel engine, characterized by a lower share of heat rejected from the exhaust and an exhaust gas temperature lower than in a spark ignition engine.

To identify realistic engine operating conditions and the corresponding exhaust gas conditions, the vehicle performed a real driving (RDE) test. The speed profile measured during the test is reported in Figure 2.

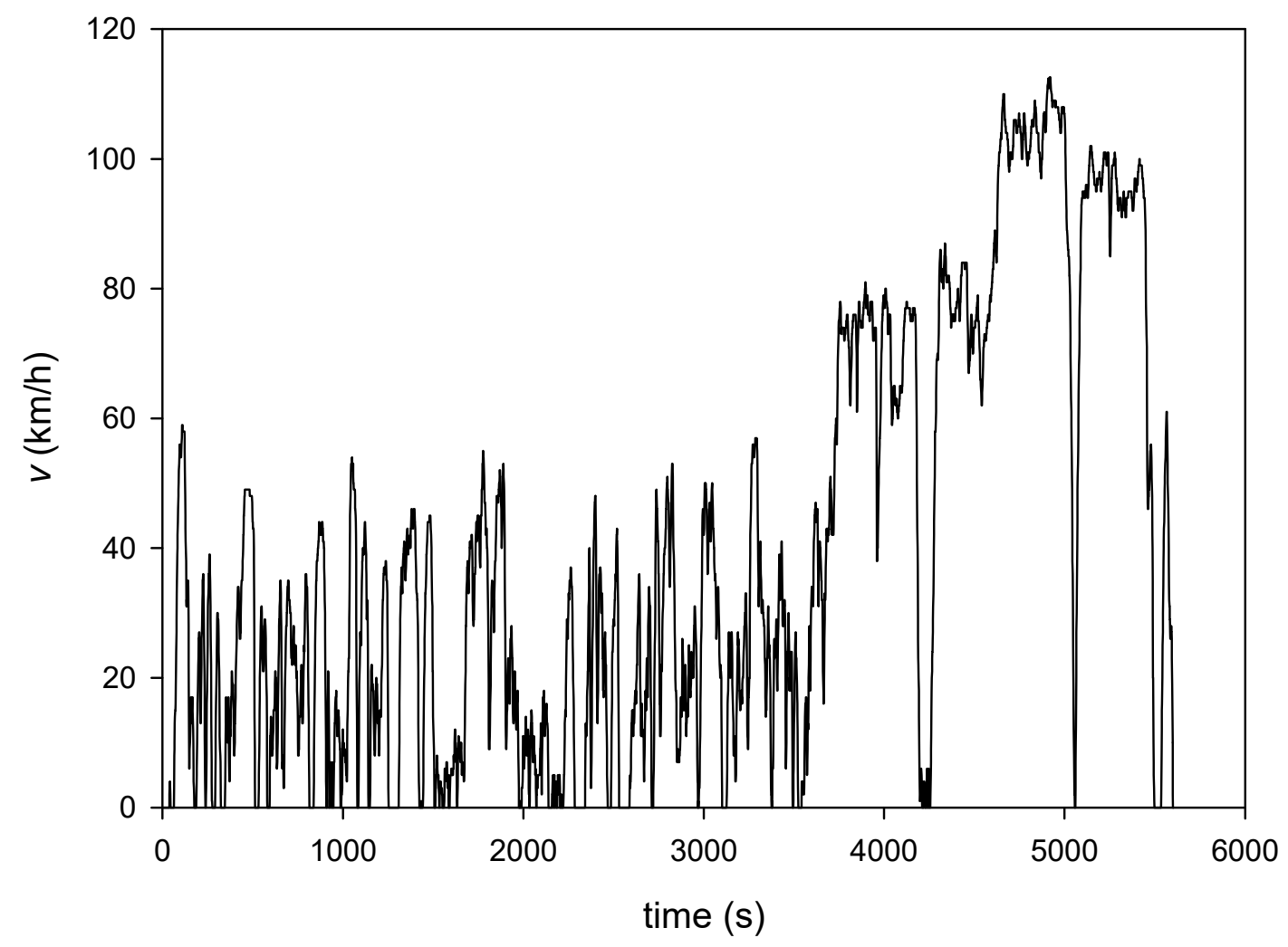

Figure 2. Instantaneous vehicle speed measured over the RDE test.

The exhaust gas mass flow rate and temperature are inputs to the ORC system performance calculations. 
Table 1 shows the engine and vehicle characteristics.

Table 1. Engine and vehicle main characteristics.

\begin{tabular}{cc}
\hline Engine type & 4-stroke turbocharged Diesel \\
Rated power & $202 \mathrm{~kW}$ at $4000 \mathrm{rpm}$ \\
Rated torque & $600 \mathrm{Nm}$ at $2200 \mathrm{rpm}$ \\
Vehicle mass & $2800 \mathrm{~kg}$ \\
Ferodynamic resistance coefficient & 0.36 \\
Frontal area & $4.17 \mathrm{~m}^{2}$ \\
Rolling resistance coefficient & 0.01 \\
\hline
\end{tabular}

During the road test, engine speed, air and fuel mass flow rates were collected from the engine control unit (ECU). A thermocouple installed downstream the exhaust aftertreatment system (EAS) was used to measure exhaust gas temperature.

Vehicle dynamic modelling allowed the determination of the instantaneous engine torque over the entire driving cycle, as plotted in Figure 3. The results clearly show that the engine mainly operated at low speed and torque, with few full load points. To reduce the number of exhaust gas conditions for simulating the ORC performance, the torque-speed values were reduced to ten grid points, as reported in Figure 4. Each engine condition was attributed to the closest grid points, with a residence time inversely proportional to the distance between such condition and the grid points. The assignment criterion imposes that the work of the engine operating point equals the sum of work of the adjacent grid points [18]. The effects of load transient on fuel consumption were neglected. The discretization makes it possible to simulate the ORC performance over the driving cycle by considering a limited number of exhaust gas mass flow rates and temperatures as input for the cycle simulation. Table 2 displays the residence time expressed as percent of the RDE test duration. The residence time is also represented in Figure 5, being proportional to the bubble area of each grid point.

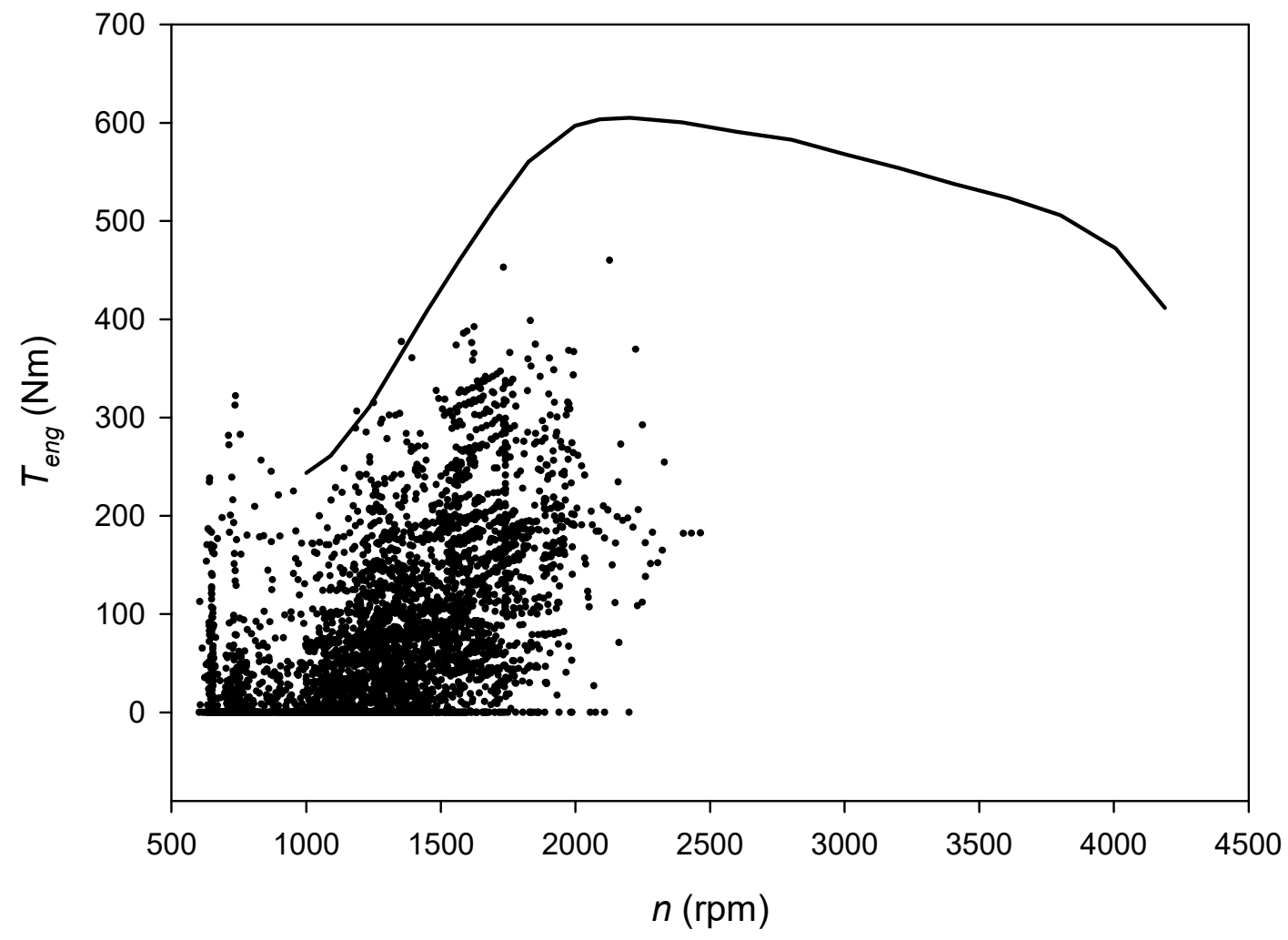

Figure 3. Engine operating points over the RDE test. 


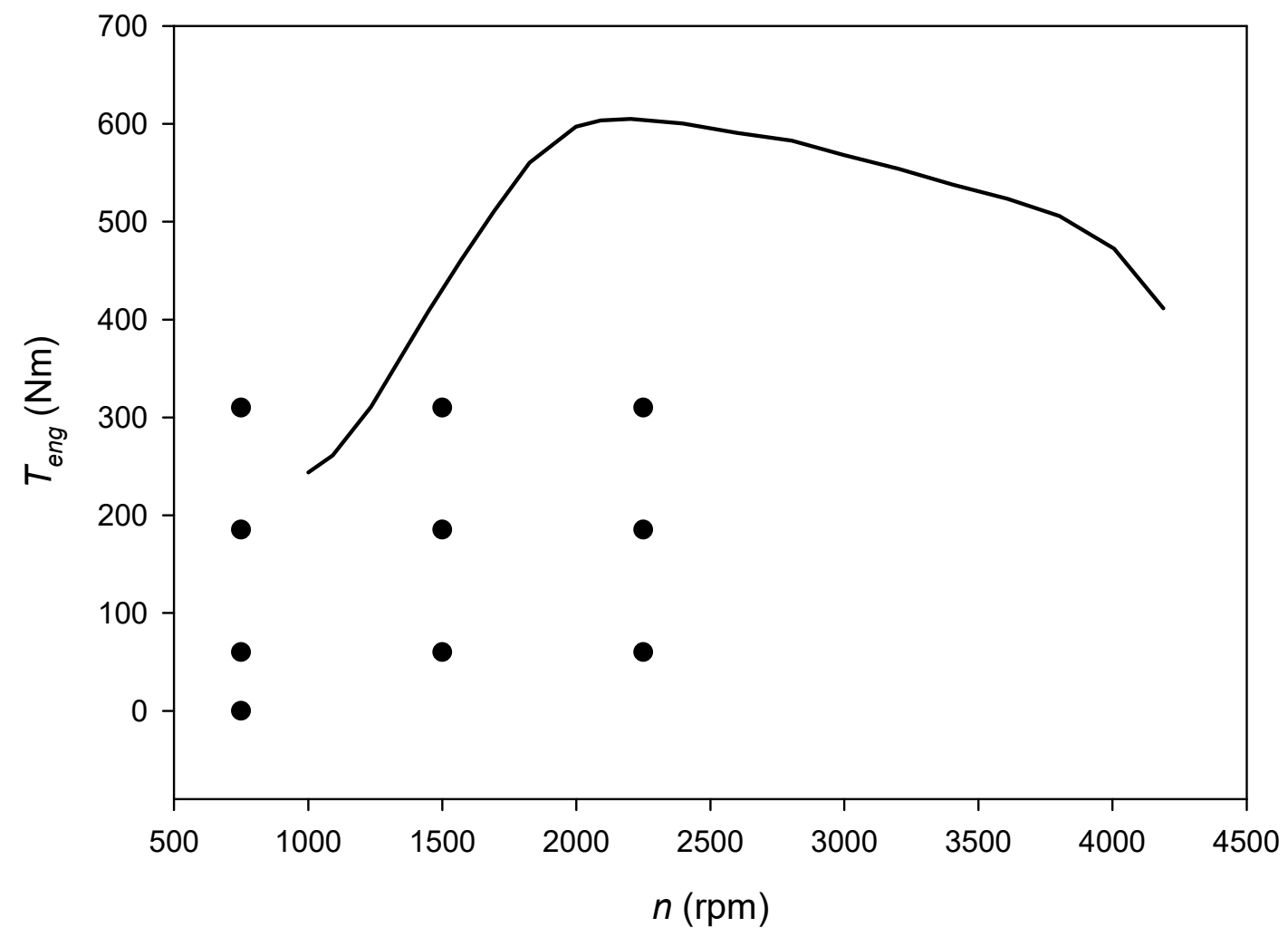

Figure 4. Torque-speed discretization grid.

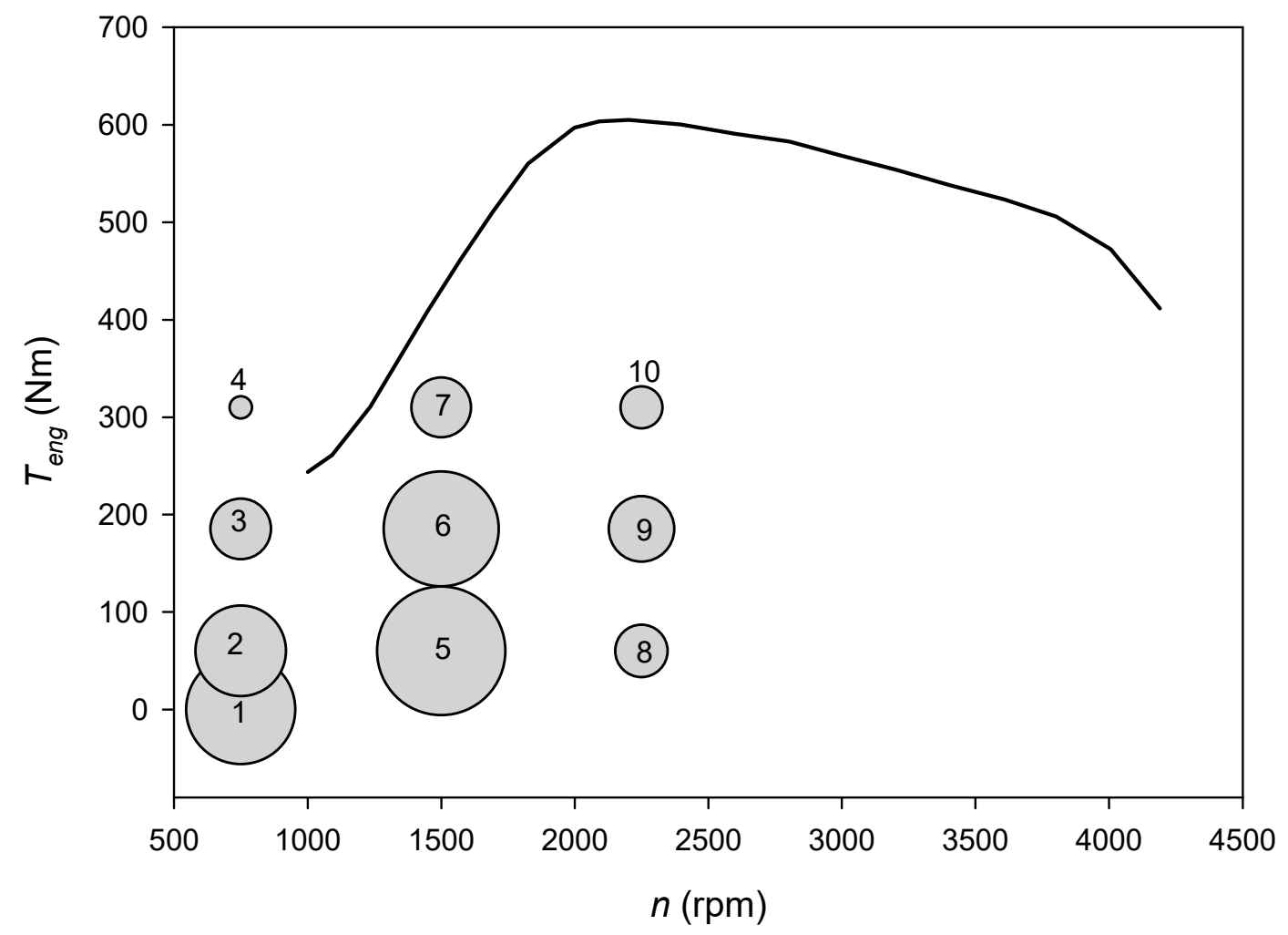

Figure 5. Engine torque curve and discretization grid points. Residence time is proportional to the bubble area. 
Table 2. Engine speed $(n)$, torque $\left(T_{\text {eng }}\right)$, percent residence time $(\tau)$, exhaust gas temperature $\left(T_{e x}\right)$ and mass flow rate $\left(m f r_{e x}\right)$ for each grid point.

\begin{tabular}{cccccc}
\hline Grid Point & $\boldsymbol{n}(\mathbf{r p m})$ & $\left.\boldsymbol{T}_{\text {eng }} \mathbf{( N ~} \mathbf{~}\right)$ & $\boldsymbol{\tau} \mathbf{( \% )}$ & $\boldsymbol{T}_{\boldsymbol{e x}}\left({ }^{\circ} \mathbf{C}\right)$ & $\boldsymbol{m f r}_{\boldsymbol{e x}}\left(\mathbf{k g ~ h} \mathbf{~}^{-\mathbf{1}}\right)$ \\
\hline 1 & 750 & 0 & 17.9 & 182 & 40 \\
2 & 750 & 60 & 12.4 & 190 & 78 \\
3 & 750 & 185 & 5.6 & 201 & 88 \\
4 & 750 & 310 & 0.8 & 207 & 92 \\
5 & 1500 & 60 & 24.8 & 207 & 117 \\
6 & 1500 & 185 & 19.8 & 242 & 147 \\
7 & 1500 & 310 & 5.4 & 266 & 184 \\
8 & 2250 & 60 & 4.1 & 243 & 174 \\
9 & 2250 & 185 & 6.5 & 263 & 206 \\
10 & 2250 & 310 & 2.7 & 279 & 222 \\
\hline
\end{tabular}

In the present study, the working fluid employed is n-pentane (R601). The ORC performance with n-pentane is compared with that obtained using R134a, a refrigerant used in car air conditioning considered as a reference fluid, but to be phased out in the near future due to its high GWP [7].

In Figure 6, a comparison between R601 and R134a is reported. R601 is a hydrocarbon belonging to the dry fluid class, while R134a is a wet fluid. Dry fluids are preferable for direct cycles because an isentropic expansion, starting at saturated vapor conditions, ends in the superheated vapor zone [19].

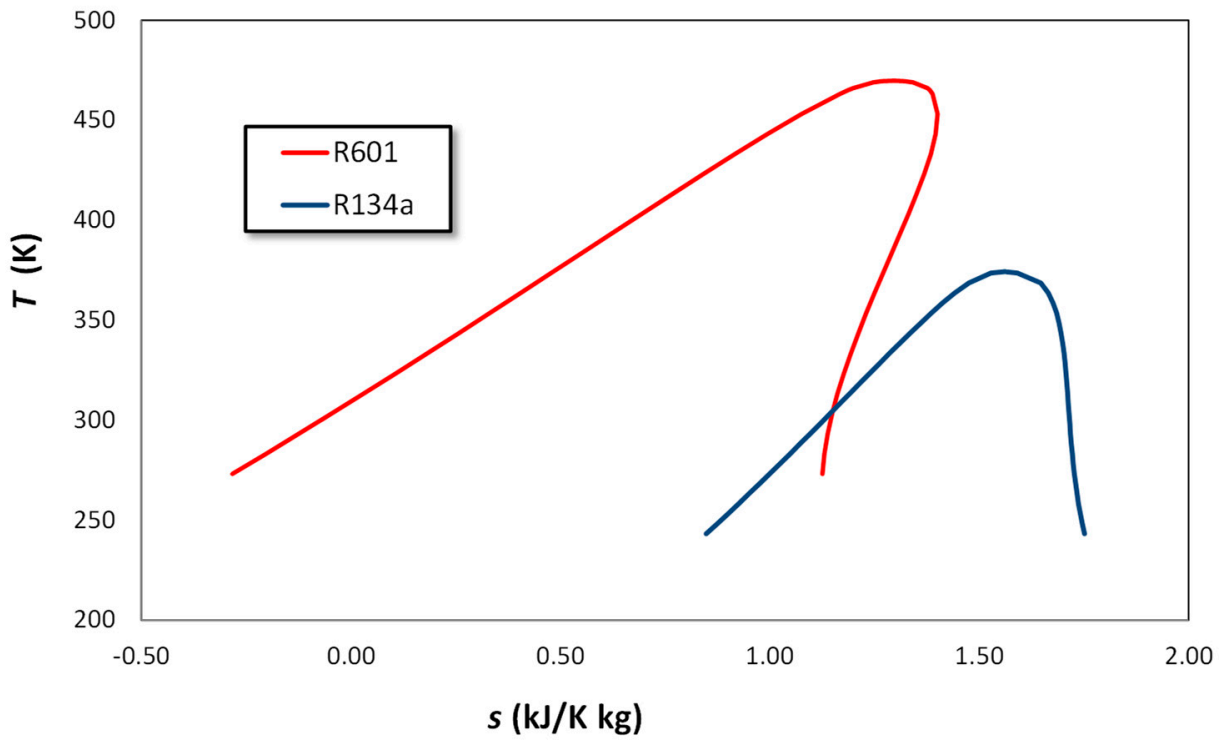

Figure 6. Saturation curves for n-pentane and R134a.

Table 3 shows some fluid thermodynamic data. R601 has a higher critical temperature while critical pressure results lower respect to R134a [20]. Both the evaporation enthalpy and the saturation temperature at 1.01 bar are higher for R601.

Table 3. Properties of the working fluids.

\begin{tabular}{ccccc}
\hline Fluid & $\boldsymbol{T}_{\boldsymbol{c r}} \mathbf{( K )}$ & $\boldsymbol{p}_{\boldsymbol{c r}} \mathbf{( B a r )}$ & $\boldsymbol{h}_{\text {evap }} \mathbf{1} \mathbf{( \mathbf { k J ~ k g } ^ { - \mathbf { 1 } } )}$ & $\boldsymbol{T}_{\text {sat }} \mathbf{1}^{\mathbf{1}} \mathbf{( K )}$ \\
\hline R601 & 469.7 & 33.70 & 357.6 & 309.1 \\
R134a & 374.2 & 40.59 & 216.9 & 247.2 \\
\hline \multicolumn{5}{c}{${ }^{1}$ At 1.01 bar. }
\end{tabular}


NFPA 704 standards consider R601 flammability high (4/4), while its health hazard is low (1/4) and no instability is observed; it does not have Ozone Depletion Potential when the 100 years Global Warming Potential is $5[7,21]$.

In addition to the ORC fluid, the expander selection is also very important for ORC systems because its performance strongly affects the actual cycle efficiency. In this case, considering the ORC system characteristics, a positive displacement expander has been selected. According to the literature, 0.70 was considered as the isentropic efficiency of the expander [22], while the pump efficiency was fixed equal to 0.65 [23,24].

Pressure losses in pipes and heat exchangers were neglected in the Rankine cycle calculations. In particular, the effect of the exhaust backpressure on engine efficiency caused by the recovery heat exchanger (RHX) was neglected, in accordance with other authors [17,25]. The effect of the ORC system mass was not considered when modelling the vehicle dynamic.

The working fluid mass flow rate was calculated assuming a totally evaporated stream at the RHX exit. The heat exchanger was assumed to be cross-flow with an overall conductance $U \cdot A$ equal to $200 \mathrm{~W} / \mathrm{K}$.

DWSIM is used to perform Rankine cycle simulations [26,27]. The software, a process simulator, is capable of modeling phase equilibria covering a variety of systems. It is able to model phase equilibria between solids, vapor and up to two liquid phase mixtures. Fluid properties were calculated using CoolProp [28], while the evaluation of fluid phase change was performed using the Nested Loop flash algorithm [27]. The program contains many components like pumps, turbines, heat exchangers which can be implemented with different solver options.

\section{Results and Discussion}

\subsection{Working Fluid Comparison}

The results in this section compare the selected working fluid R601 with R134a. In particular, the two fluids are compared varying the pressure increase in the pump from 5 to $20 \mathrm{bar}$. The condensation temperature is $314 \mathrm{~K}$, a value motivated by the assumption that the cold fluid in the condenser is air at ambient conditions, assuming a minimum temperature difference between the fluids of $15 \mathrm{~K}$. The maximum ORC pressure is different for each fluid since the saturation pressures in the condenser at $T_{1}=314 \mathrm{~K}$ are different, Table 4 . The maximum pressures range from 6.2 to $21.2 \mathrm{bar}$ for R601 and from 15.4 to 30.4 bar for R134a.

Table 4. Cycle temperatures and pressures.

\begin{tabular}{cccc}
\hline Fluid & $\boldsymbol{T}_{\mathbf{1}}(\mathrm{K})$ & $\boldsymbol{P}_{\mathbf{1}}$ (Bar) & $\boldsymbol{P}_{\mathbf{2}}$ (Bar) \\
\hline R601 & 314 & 1.2 & $6.2-21.2$ \\
R134a & 314 & 10.4 & $15.4-30.4$ \\
\hline
\end{tabular}

Engine exhaust mass flow rate and temperature are $147 \mathrm{~kg} \mathrm{~h}^{-1}$ and $515 \mathrm{~K}$, respectively (grid point 6 in Table 2), this condition being the most representative one in terms of recovered heat over the entire test.

The actual Rankine cycle for R601 is represented in Figure 7.

The working fluid mass flow rate is adjusted according to the maximum cycle pressure in order to have complete vaporization at the RHX outlet, i.e., vapor quality $x=1.0$. The results are reported in Figure 8 for the two investigated fluids. Both fluids show a slightly decreasing trend of mass flow rate as pressure increases. The different values for the two fluids are consequence of higher heat required for the vaporization of R601 compared with R134a. 


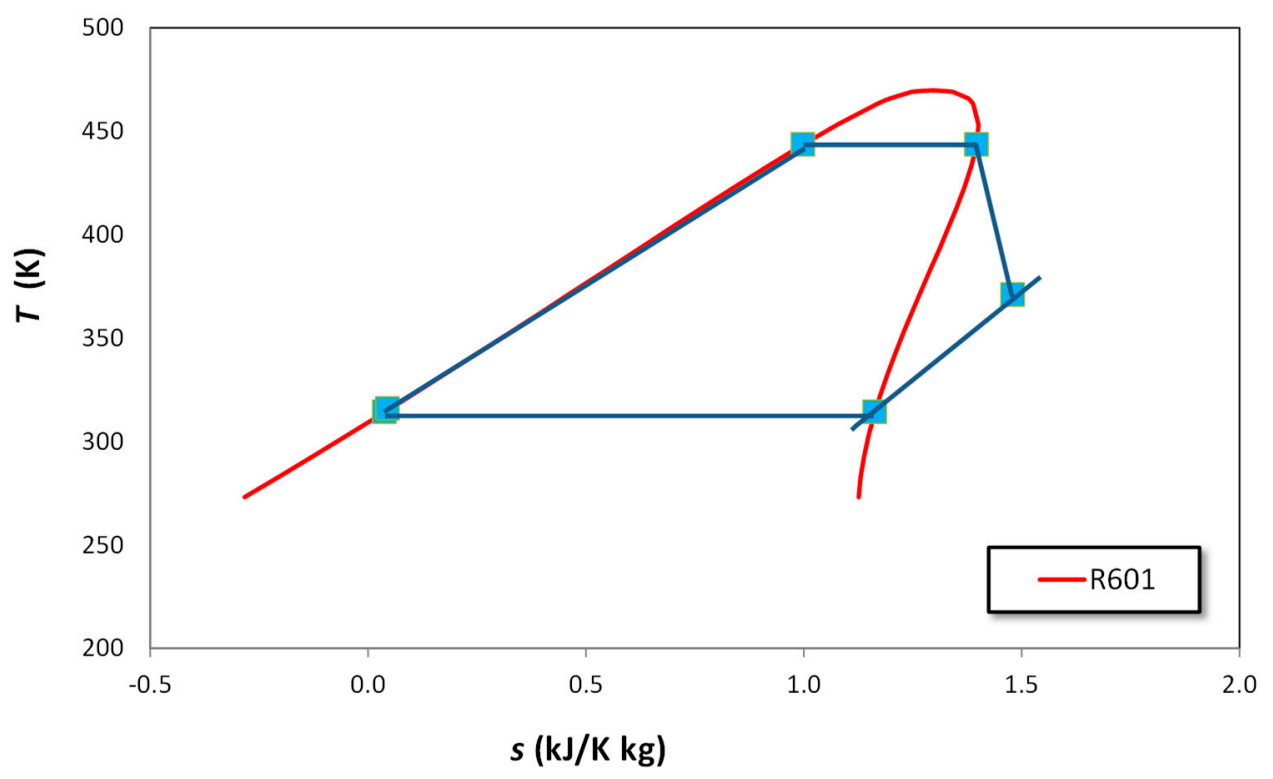

Figure 7. Actual Rankine cycle in the temperature-entropy diagram.

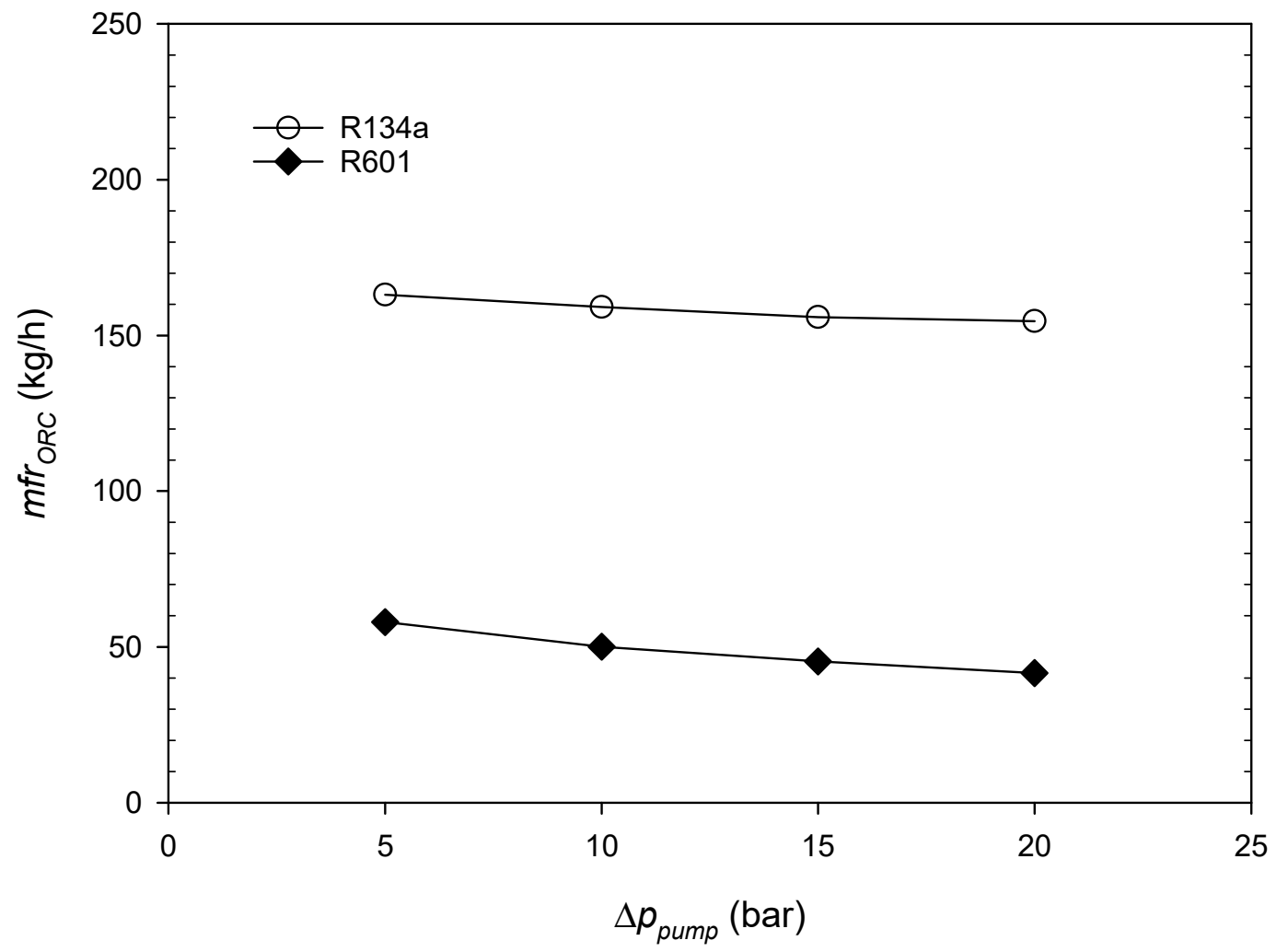

Figure 8. Working fluid mass flow rate as a function of pump pressure increase, grid point 6 .

ORC system power increases with pump differential pressure, Figure 9. This trend is related to the cycle efficiency, as confirmed by Figure 10. The ORC power is larger when using the R601 fluid, with figures almost double than those obtained with R134a. This occurs although the maximum pressure values are lower. In fact, R601 maximum cycle pressure ranges from 6.2 to 26.2 bar, while for R134a it is from 15.4 to 30.4 bar. Obviously, the larger the values of the maximum cycle pressure, the heavier the ORC plant for structural and safety reasons. 


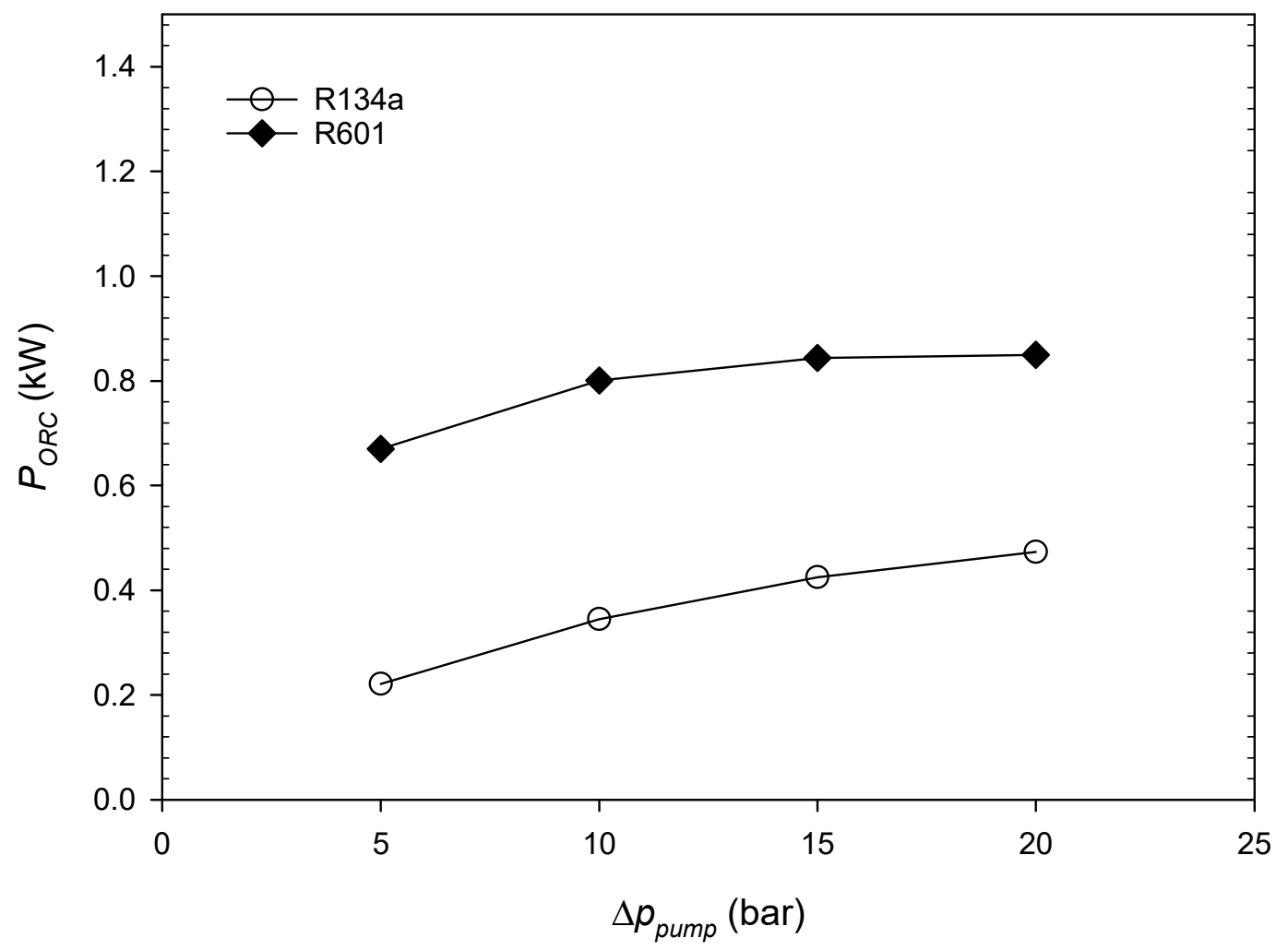

Figure 9. ORC power as a function of pump pressure increase, grid point 6 .

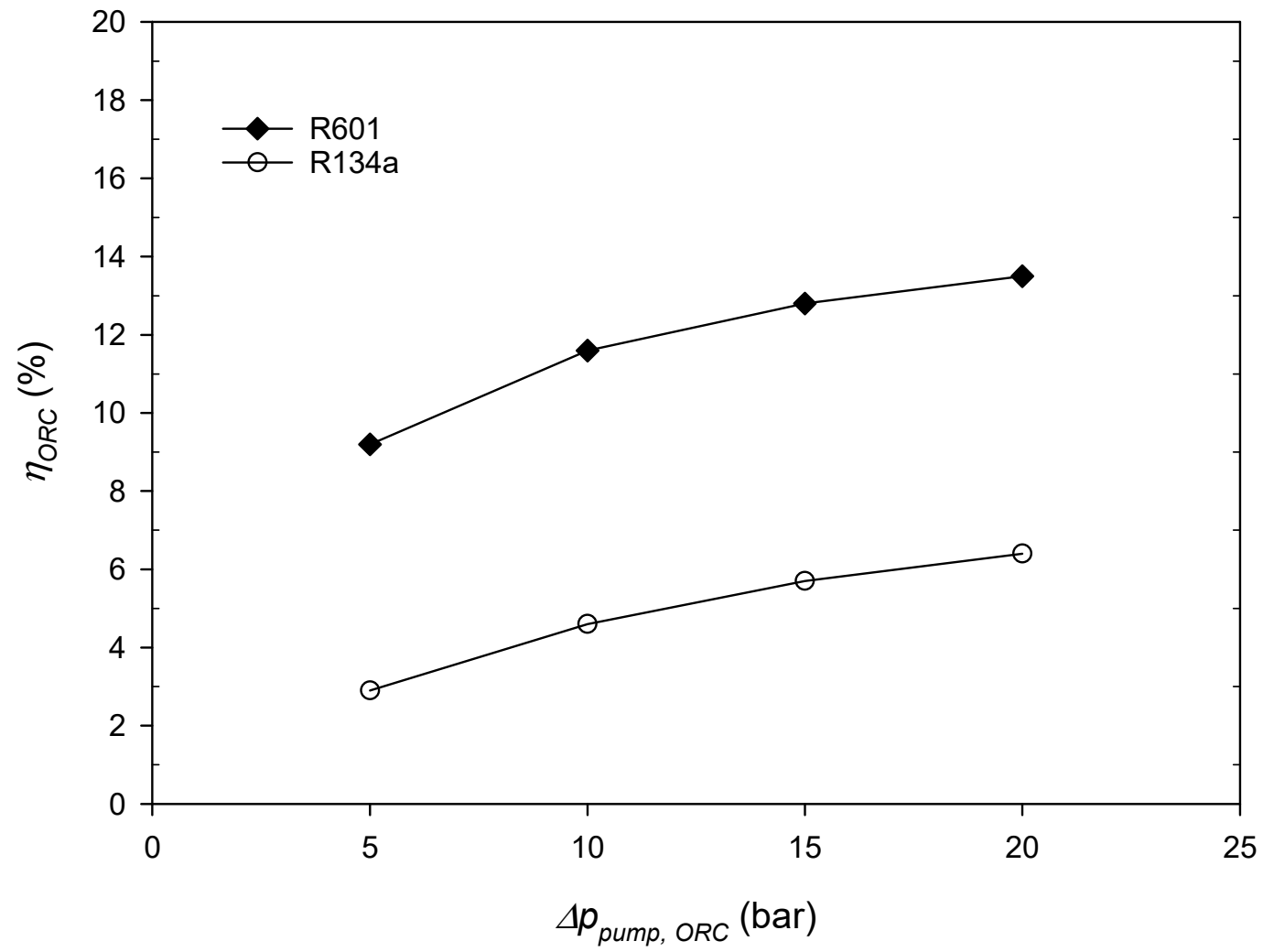

Figure 10. ORC efficiency as a function of pump pressure increase, grid point 6 . 
ORC efficiency is evaluated according to Equation (1):

$$
\eta_{\text {ORC }}=\frac{P_{\text {ORC }}}{m f r_{e x} \cdot c_{p, e x}\left(T_{e x, \text { in }}-T_{e x, o u t}\right)}
$$

where $P_{\text {ORC }}$ is the ORC power output, $c_{p, e x}$ the specific heat of the exhaust gases, $m f r_{e x}$ the exhaust mass flow rate, and $T_{e x, \text { in }}$ and $T_{e x, o u t}$ the exhaust gas temperatures at the inlet and outlet of the RHX.

Figure 10 shows the results of the calculations at grid point 6, comparing the ORC efficiency of the two fluids, as a function of the pump differential pressure. While R134a shows values in the range 2.9 to $6.5 \%$, the values for R601 are much higher, with results between 9.2 and $13.5 \%$.

The effect of the ORC power contribution can be evaluated determining the engine efficiency increment calculated according to Equation (2):

$$
\Delta \eta_{\text {eng }} / \eta_{\text {eng }}=\frac{P_{\text {ORC }}}{P_{\text {eng }}} \times 100
$$

Figure 11 shows the calculated results comparing the performance of the two working fluids as a function of the pressure increase in the pump. R601 shows engine efficiency increment between 2.3 and $2.9 \%$, whereas R134a displays an increment between $0.8 \%$ and $1.6 \%$.

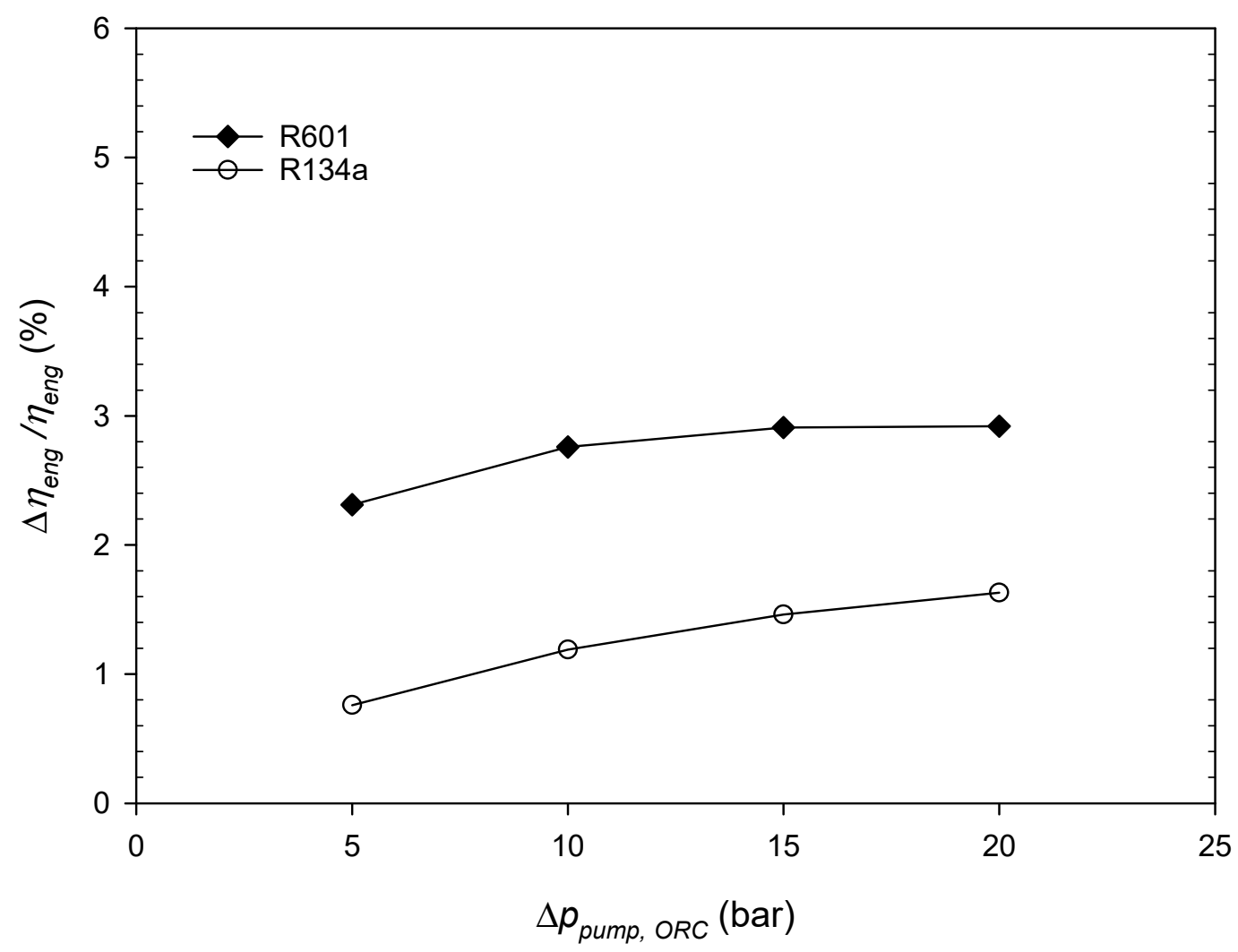

Figure 11. Engine efficiency increment as a function of the pump pressure increase, grid point 6 .

Thus, R601 is the preferred fluid as working fluid for ORC not only because R134a is to be phased out due to its environmental impact, but mainly because of its better performance.

\subsection{ORC Performance with R601}

The ORC performance over the RDE test is evaluated considering the heat recovered from the exhaust gases of the internal combustion engine in the driving operating conditions, corresponding to 
the grid nodes, each one characterized by a residence time. The working fluid considered is R601 and the pump differential pressure 20 bar.

The ORC power depends on the available heat recovered from the engine exhaust gases. At higher engine loads and speeds, the exhaust mass flow rate and temperature also increase, and consequently the ORC delivers more power, Figure 12, whose values range between 0.2 and $1.3 \mathrm{~kW}$. The maximum power of $1.3 \mathrm{~kW}$ is produced from the ORC plant when the engine operates at condition represented by grid point 10 .

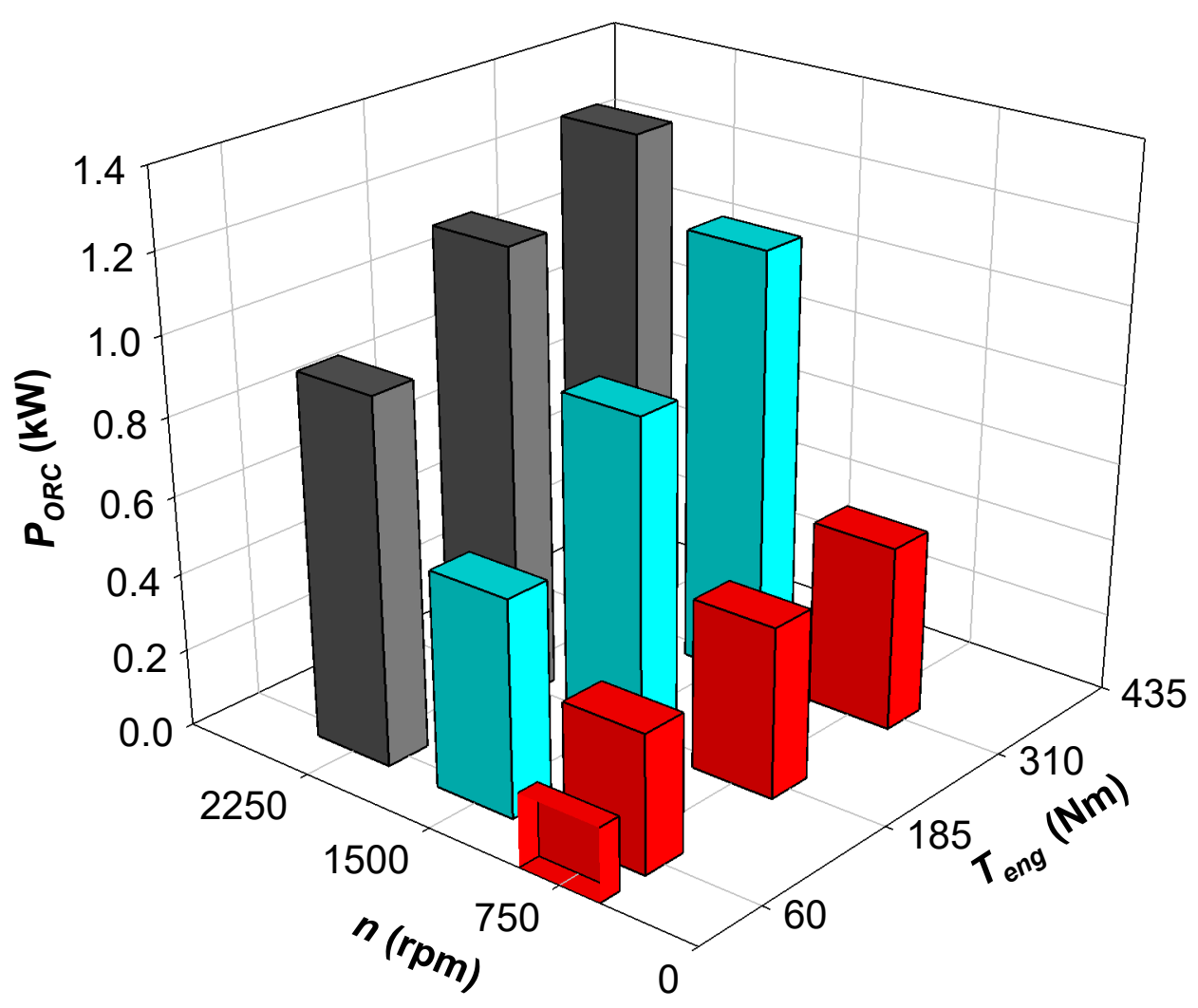

Figure 12. ORC delivered power at the engine operating points of the discretization grid.

The efficiency of the ORC system mainly depends on the maximum cycle pressure and temperature. In this analysis, the pressure increase in the pump is held constant for all grid nodes and the working fluid mass flow rate adjusted for a complete vaporization of the fluid into the RHX, i.e., working fluid maximum temperature is also constant and equal to $442 \mathrm{~K}$. For this reason, there is not a meaningful variation of the ORC efficiency between grid nodes, as confirmed by the results displayed in Figure 13. In fact, the efficiency of the cycle is almost constant for all grid points, with values around $13 \%$.

The ORC power contribution results in an increase of engine efficiency. This increment is displayed in Figure 14 for all grid nodes. The highest values, between $6.6 \%$ and $7.5 \%$, were attained at part load, while increments between $1.8 \%$ and $2.3 \%$ were obtained at high loads. This result, apparently unexpected, since Figure 12 shows that at higher loads and speeds the ORC delivers more power, can be easily interpreted. In fact, the efficiency increment depends on the ratio between the ORC power and the engine power, Equation (2), resulting in a higher efficiency increment for operating conditions where the engine power is small. By considering the residence time at each discretized operating condition, the average engine efficiency increment over the RDE test is $4.6 \%$. 


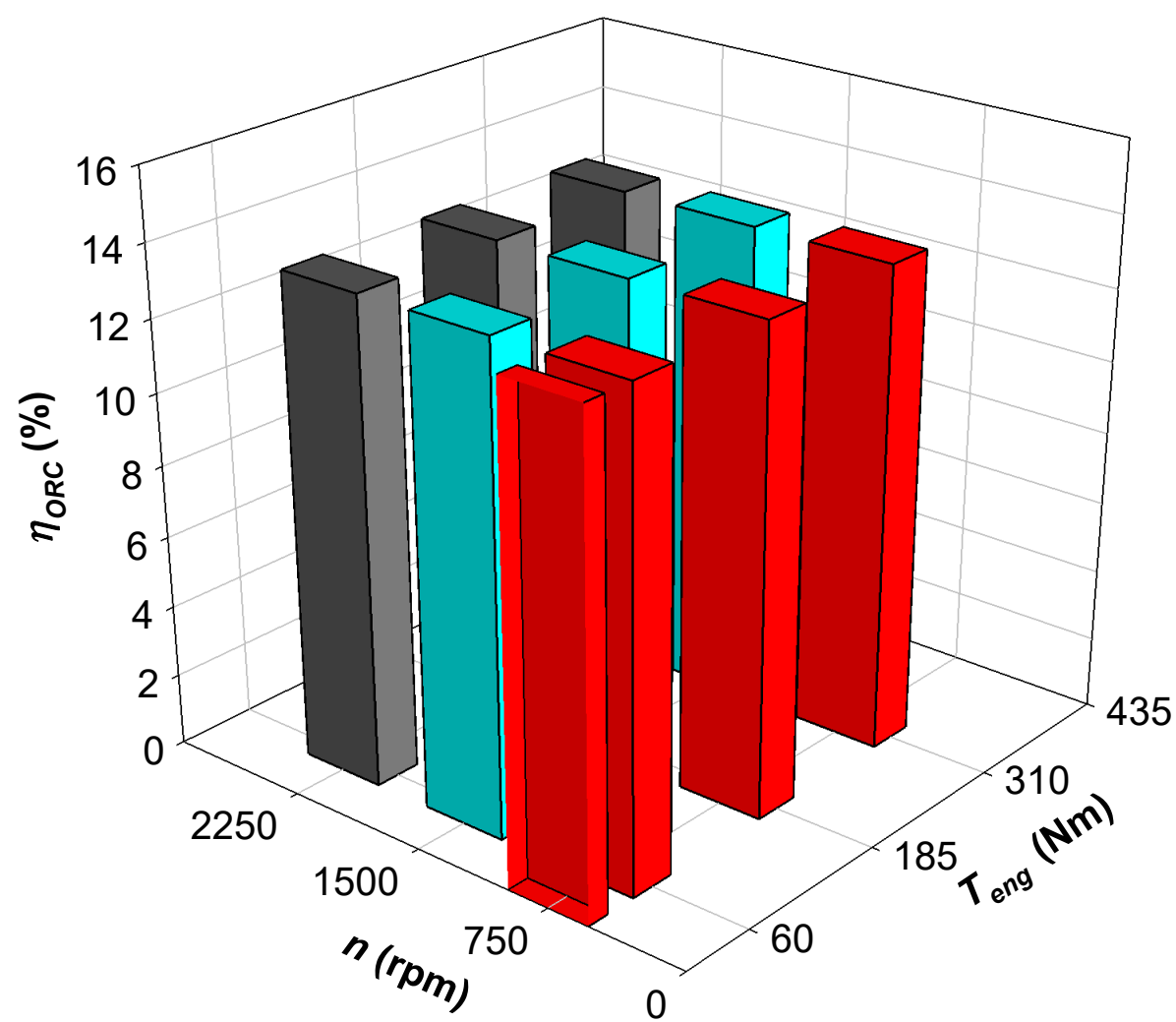

Figure 13. ORC efficiency at the engine operating points of the discretization grid.

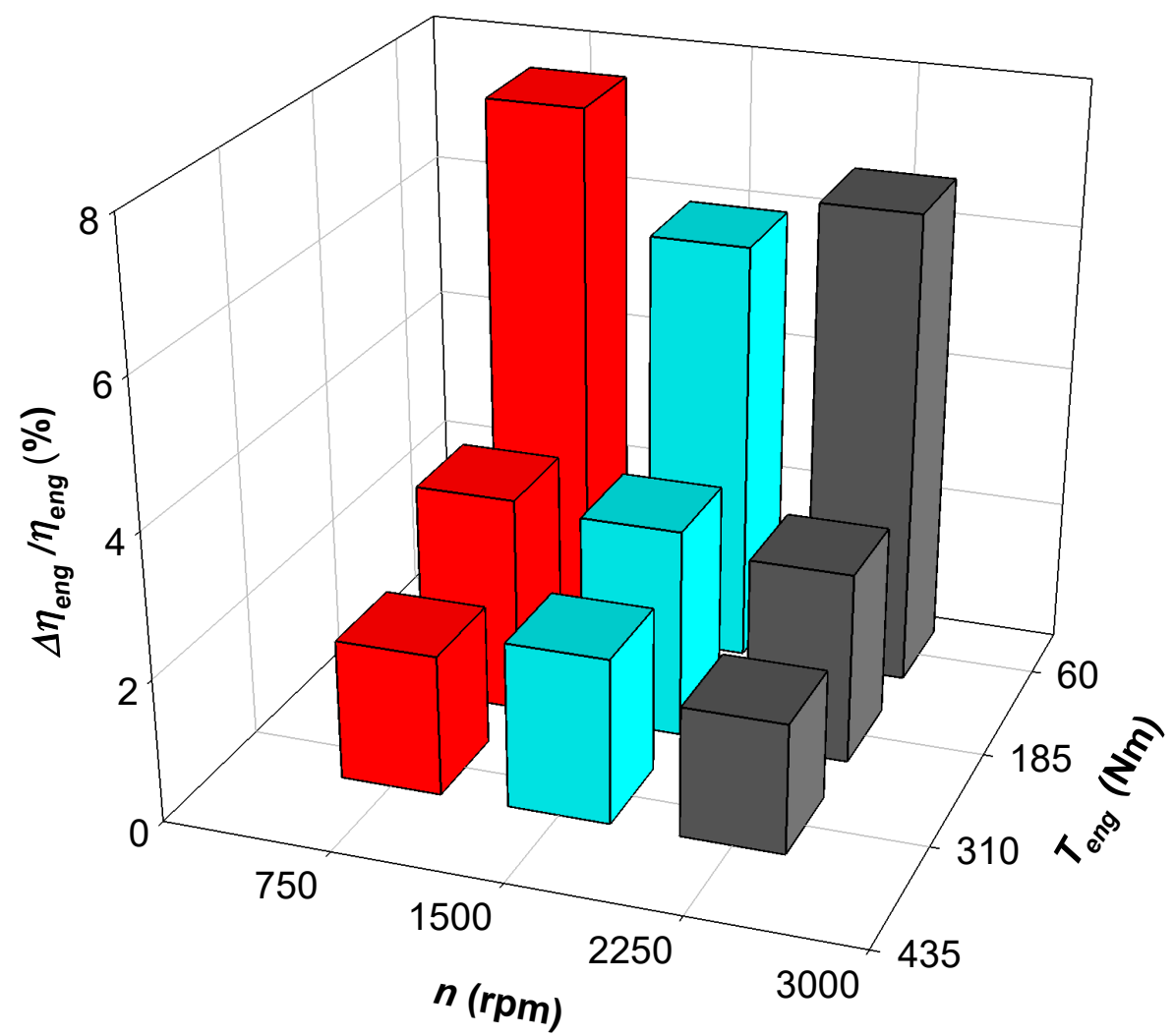

Figure 14. Engine efficiency increment at the engine operating points of the discretization grid. 


\section{Conclusions}

A passenger car powered by a compression ignition engine was tested on an RDE cycle and the thermal power available in the exhaust gases exploited into an ORC system in order to promote an engine efficiency increase. The ORC calculations were accomplished using n-pentane (R601) as working fluid, while R134a was identified as a reference fluid for comparison purposes. To reduce the number of exhaust gas conditions for simulating the ORC performance, engine torque-speed values determined over the RDE test were discretized using a ten-point grid characterized by a residence time. The discretization makes it possible to calculate the ORC power, Rankine cycle efficiency and engine efficiency increment over the driving cycle by considering only a limited number of exhaust gas conditions as input for the cycle analysis.

The constrained R601 mass flow rate was higher than that required with R134a as working fluid, due to the different thermo-physical characteristics of the fluids. The ORC power and efficiency were also higher for R601 when the engine was operating at $185 \mathrm{Nm}$ and $1500 \mathrm{rpm}$, the engine condition at which the two fluids were compared.

The ORC delivered power increased with the engine load and speed, since the exhaust mass flow rate and temperature were high. The ORC power ranged between 0.2 and $1.3 \mathrm{~kW}$, with the maximum power of $1.3 \mathrm{~kW}$ obtained at $310 \mathrm{Nm}$ and $2250 \mathrm{rpm}$. The Rankine cycle efficiency was almost constant at all grid node points, with values around $13 \%$. This was due to the fact that the ORC operating parameters, such as maximum cycle pressure and temperature, did not change for all the employed grid points.

The engine efficiency increase related to the ORC power was calculated. The highest values, between $6.6 \%$ and $7.5 \%$, were obtained at low engine loads, while lower increments, between $1.8 \%$ and $2.3 \%$, corresponded to high load conditions. This result, apparently unexpected, can be easily interpreted. In fact, the efficiency increment depends on the ratio between the ORC power and the engine power, resulting in higher efficiency increment for operating conditions where the engine power is small.

The averaged engine efficiency increment on the RDE test was $4.6 \%$, considering the residence time at each discretized operating condition as the weight for the average process.

In conclusion, the ORC system is a promising solution for increasing the efficiency of internal combustion engines. The analysis is performed considering actual exhaust gas conditions of a diesel engine, which displays a less favorable (low temperature) waste heat source compared with a spark ignition engine.

Author Contributions: Conceptualization, A.M., M.L.M., B.M., M.V.P. and A.U.; methodology, A.M., B.M., M.V.P. and A.U.; investigation, A.M., M.L.M., B.M., M.V.P. and A.U.; data analysis, A.M., M.L.M., B.M., M.V.P. and A.U.; writing-original draft preparation, A.M.; writing-review and editing, A.M., B.M. and A.U. All authors have read and agreed to the published version of the manuscript.

Funding: This research received no external funding.

Conflicts of Interest: The authors declare no conflict of interest.

\section{Nomenclature}

$\begin{array}{ll}A & \text { Area }\left(\mathrm{m}^{2}\right) \\ c_{p} & \text { Specific Heat }(\mathrm{kJ} /(\mathrm{kg} \mathrm{K})) \\ \text { EAS } & \text { Exhaust After-treatment System } \\ \text { ECU } & \text { Engine Control Unit } \\ \text { eng } & \text { Engine } \\ \text { ICE } & \text { Internal Combustion Engine } \\ m f r & \text { Mass flow rate }(\mathrm{kg} / \mathrm{s}) \\ n & \text { Engine rotational speed }(\mathrm{rpm}) \\ \text { ORC } & \text { Organic Rankine Cycle } \\ p & \text { Pressure (bar) }\end{array}$




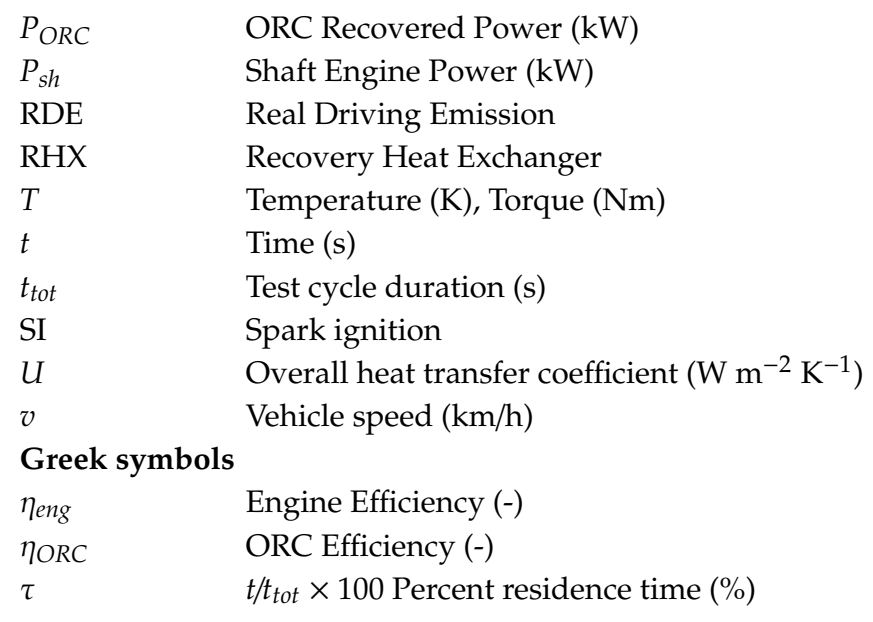

\section{References}

1. Kyoto Protocol. Available online: https://unfccc.int/resource/docs/convkp/kpeng.pdf (accessed on 6 December 2019).

2. Regulation (EC) No 443/2009 of the European Parliament and of the Council of 23 April 2009 setting emission performance standards for new passenger cars as part of the community's integrated approach to reduce $\mathrm{CO}_{2}$ emissions from light-duty vehicles. Off. J. Eur. Union 2009. Available online: https: //eur-lex.europa.eu/legal-content/EN/TXT/?uri=CELEX\%3A32009R0443 (accessed on 6 December 2019).

3. Oil and Petroleum Products—A Statistical Overview. Available online: https://ec.europa.eu/eurostat/statisticsexplained/index.php?title=Oil_and_petroleum_products_-_a_statistical_overview\&oldid=404136 (accessed on 12 November 2019).

4. Heywood, J. Internal Combustion Engine Fundamentals; Mc Graw-Hill: New York, NY, USA, 1989.

5. Stuhldreher, M.; Kargul, J.; Barba, D.; McDonald, J.; Bohac, S.; Dekraker, P.; Moskalik, A. Benchmarking a 2016 Honda Civic 1.5-Liter L15B7 Turbocharged Engine and Evaluating the Future Efficiency Potential of Turbocharged Engines. SAE Int. J. Engines 2018, 11, 1273-1305. [CrossRef] [PubMed]

6. Lion, S.; Michos, C.N.; Vlaskos, I.; Taccani, R. A thermodynamic feasibility study of an Organic Rankine Cycle (ORC) for heavy-duty diesel engine waste heat recovery in off-highway applications. Int. J. Energy Environ. Eng. 2017, 8, 81-98. [CrossRef]

7. Lion, S.; Michos, C.N.; Vlaskos, I.; Rouaud, C.; Taccani, R. A review of waste heat recovery and Organic Rankine Cycles (ORC) in on-off highway vehicle Heavy Duty Diesel Engine applications. Renew. Sustain. Energy Rev. 2017, 79, 691-708. [CrossRef]

8. Dai, Y.; Wang, J.; Gao, L. Parametric optimization and comparative study of organic Rankine cycle (ORC) for low grade waste heat recovery. Energy Convers. Manag. 2009, 50, 576-582. [CrossRef]

9. Nazari, N.; Heidarnejad, P.; Porkhial, S. Multi-objective optimization of a combined steam-organic Rankine cycle based on exergy and exergo-economic analysis for waste heat recovery application. Energy Convers. Manag. 2016, 127, 366-379. [CrossRef]

10. Xu, B.; Rathod, D.; Yebi, A.; Filipi, Z. A comparative analysis of real-time power optimization for organic Rankine cycle waste heat recovery systems. Appl. Therm. Eng. 2020, 164, 114442. [CrossRef]

11. Chen, H.; Goswami, D.Y.; Stefanakos, E.K. A review of thermodynamic cycles and working fluids for the conversion of low-grade heat. Renew. Sustain. Energy Rev. 2010, 14, 3059-3067. [CrossRef]

12. Maizza, V.; Maizza, A. Unconventional working fluids in organic Rankine-cycles for waste energy recovery systems. Appl. Therm. Eng. 2001, 21, 381-390. [CrossRef]

13. NFPA. Available online: https://www.nfpa.org/ (accessed on 28 August 2019).

14. EPA Greenhouse Gas Emissions. Available online: https://www.epa.gov/ghgemissions/understandingglobal-warming-potentials (accessed on 30 September 2019).

15. Hountalas, D.T.; Mavropoulos, G.C.; Katsanos, C.; Knecht, W. Improvement of bottoming cycle efficiency and heat rejection for HD truck applications by utilization of EGR and CAC heat. Energy Convers. Manag. 2012, 53, 19-32. [CrossRef] 
16. Valencia, G.; Fontalvo, A.; Cárdenas, Y.; Duarte, J.; Isaza, C. Energy and exergy analysis of different exhaust waste heat recovery systems for natural gas engine based on ORC. Energies 2019, 12, 2378. [CrossRef]

17. Michos, C.N.; Lion, S.; Vlaskos, I.; Taccani, R. Analysis of the backpressure effect of an Organic Rankine Cycle (ORC) evaporator on the exhaust line of a turbocharged heavy duty diesel power generator for marine applications. Energy Convers. Manag. 2017, 132, 347-360. [CrossRef]

18. Mariani, A.; Morrone, B.; Unich, A. Numerical evaluation of internal combustion spark ignition engines performance fuelled with hydrogen-Natural gas blends. Int. J. Hydrogen Energy 2012, 37, 2644-2654. [CrossRef]

19. He, C.; Liu, C.; Gao, H.; Xie, H.; Li, Y.; Wu, S.; Xu, J. The optimal evaporation temperature and working fluids for subcritical organic Rankine cycle. Energy 2012, 38, 136-143. [CrossRef]

20. Bao, J.; Zhao, L. A review of working fluid and expander selections for organic Rankine cycle. Renew. Sustain. Energy Rev. 2013, 24, 325-342. [CrossRef]

21. ASHRAE Update on New Refrigerants Designations and Safety Classifications. Available online: https: //www.ashrae.org/technical-resources/standards-and-guidelines/ashrae-refrigerant-designations (accessed on 12 November 2019).

22. Glavatskaya, Y.; Podevin, P.; Lemort, V.; Shonda, O.; Descombes, G. Reciprocating expander for an exhaust heat recovery rankine cycle for a passenger car application. Energies 2012, 5, 1751-1765. [CrossRef]

23. Mastrullo, R.; Mauro, A.W.; Revellin, R.; Viscito, L. Modeling and optimization of a shell and louvered fin mini-tubes heat exchanger in an ORC powered by an internal combustion engine. Energy Convers. Manag. 2015, 101, 697-712. [CrossRef]

24. Declaye, S.; Quoilin, S.; Guillaume, L.; Lemort, V. Experimental study on an open-drive scroll expander integrated into an ORC (Organic Rankine Cycle) system with R245fa as working fluid. Energy 2013, 55, 173-183. [CrossRef]

25. Katsanos, C.O.; Hountalas, D.T.; Pariotis, E.G. Thermodynamic analysis of a Rankine cycle applied on a diesel truck engine using steam and organic medium. Energy Convers. Manag. 2012, 60, 68-76. [CrossRef]

26. Leino, M. Process Simulation Unit Operation Models—Review of Open and Hsc Chemistry I/O Interfaces; Tampere University of Technology: Tampere, Finland, 2016.

27. DWSIM. Available online: http://dwsim.inforside.com.br/wiki/index.php?title=DWSIM (accessed on 12 November 2019).

28. Bell, I.H.; Wronski, J.; Quoilin, S.; Lemort, V. Pure and pseudo-pure fluid thermophysical property evaluation and the open-source thermophysical property library coolprop. Ind. Eng. Chem. Res. 2014, 53, 2498-2508. [CrossRef] [PubMed]

(C) 2020 by the authors. Licensee MDPI, Basel, Switzerland. This article is an open access article distributed under the terms and conditions of the Creative Commons Attribution (CC BY) license (http://creativecommons.org/licenses/by/4.0/). 